\title{
Desenvolvimento da floresta amazônica: problemas prioritários para a formulação de diretrizes
}

Philip M. Fearnside *

Nesta nota, tentarei identificar algumas das áreas principais, em que ecólogos podem e devem contribuir para o esforço atual de formular diretrizes adequadas ao desenvolvimento da Amazônia brasileira. Embora existam muitas áreas importantes para a política do desenvolvimento, vou concentrar-me nas mais relacionadas com o atual esforço, para esclarecer o rumo futuro do aproveitamento do recurso natural mais singular da região: a floresta amazônica, divididas as áreas prioritárias, neste sentido, em seis categorias : 1) capacidade de suporte e colonização; 2) extensão do desmatamento; 3) efeitos do desmatamento; 4j causas do desmatamento; 5) controle do desmatamento, e 6) usos planejados da floresta (Fearnside, 1979c).

\section{CAPACIDADE DE SUPORTE E COLONIZAÇÃO}

Coloco esta consideração na cabeça da lista, face à sua importância enorme e ao efeito sobre todas as demais possíveis considerações relativas ao desenvolvimento da Amazônia. Cada tipo de desenvolvimento implica na sustentação de uma população humana. O número de pessoas que podem ser sustentadas pelos diferentes projetos depende do tipo de colonização, do tipo de tecnologia produtiva empregado, do padrão de vida a ser desfrutado pela população, e das probabilidades de falha, em termos de diferentes critérios, considerados aceitáveis pelos planejadores. O fato de que planejadores não disponham de (e não exijam) informações concretas sobre estes tipos de considerações, no processo de formular planos para desenvolvimento na Amazônia, implica num grande perigo de falha nos planos, tanto do ponto de vista de sustentar a população humana dentro de um padrão adequado, quanto do ponto de vista de evitar degradação do meio ambiente nestas áreas. A contribuição cee ecólogos no desenho de investigações sobre capacidade de suporte dos diferentes tipos de exploração considerados é essencial.

\section{EXTENSÃO DO DESMATAMENTO}

Considerando a importância de informações sobre a extensão das áreas desmatadas e a taxa de desmatamento, o nível de conhecimento sobre o assunto é péssimo. Os jornais e a bibliografia contêm um aspecto enorme de estimativas e opiniões sobre o assunto estão baseadas em pouquíssimos dados. A estimativa mais bem feita, usando imagens LANDSAT, confunde a situação pela inclusão de uma grande área de cerrado na área mostrada, chegando até a incluir áreas de Goiás na latitude do Distrito Federal de Brasília na amostra (Tardin et al., 1979). O valor de 3,8\% apresentado refere-se à porcentagem desta área total desmatada até agosto de 1976 (Tardin et al., 1978), não sendo interpretáveis os dados específicos à área da mata amazônica em termos de porcentagem desmatada. Este estudo do Instituto Nacional de Pesquisas Espaciais (INPE) está mais voltado à demonstração da aplicabilidade da tecnologia de sensoreamento remoto à quantificação de desmatamento, e este objetivo foi bem alcançado.

Acompanhamento minucioso dos desmatamentos na Amazônia deveria ter uma alta prioridade, com adequado reconhecimento de campo para completar os dados provenientes do sensoreamento remoto. O desenvolvimento da capacidade para realizar estudos baseados em sensoreamento remoto na própria Amazônia, preferivelmente no INPA, deve ser um alvo importante para garantir que os benefícios destes estudos sejam os mais relevantes possível às pesquisas complementares de campo realizadas aqui. Precisa-se tanto de facilidades para interpretação de fotografia aérea, quanto de imagens LANDSAT e mosaicos do Projeto 
RADAM. Claramente, facilidades de computação eletrônica têm que ser ligadas com tais laboratórios.

Todavia, deve ser enfatizado que a falta de dados minuciosos sobre a extensão e a taxa de desmatamento não deveria ser usada como desculpa para procrastinar a tomada de medidas imediatas e efetivas para freiar este processo na Amazônia.

\section{EFEITOS DO DESMATAMENTO}

A importância deste assunto já é bem reconhecida. Estudos dos efeitos de desmatamento sobre o clima global e local, principalmente em termos de pluviosidade e temperatura, dão justa causa para preocupação, e deveriam ser continuados em rítmo acelerado. Estudos sobre os efeitos na fertilidade do solo, na erosão, e nos ciclos de vários elementos também merecem atenção prioritária. A óbvia ligação do desmatamento com a extinção de muitas espécies, comunidades e ecossistemas, justifica o contínuo estudo, publicidade e debates destes efeitos infelizes. O efeito do desmatamento sobre populações humanas que dependem da floresta, principalmente populações indígenas, mas também incluindo populações de seringueiros, caçadores, castanheiros e outros grupos, claramente cai nesta categoria também.

\section{CAUSAS DO DESMATAMENTO}

Qualquer política de desenvolvimento visando a limitar efetivamente o desmatamento deverá ser baseada sobre o conhecimento das causas básicas que vêm motivando este processo. Qualquer programa de regulamentos, mesmo com finalidade a mais racional e desejável possível, vai acabar em fracasso, caso não considerem estas conseqüências fundamentais de desmatamento.

Uma revisão de todos os programas de incentivos fiscais e tributários do governo, e dos seus efeitos sobre o desmatamento, é urgente. Por exemplo, projetos de pecuária bovina vêm gozando de enormes incentivos : empréstimos sem juros (mas com correção monetária) com dois anos de carência e um prazo que no início do programa era de sete anos e agora é de cinco anos. Estes projetos também têm o privilégio de aplicar uma parte do imposto de renda devido, na capitalização da empresa, e além disso, um programa para dar ao pecuarista o uso de dinheiro colhido em imposto de renda de outros pagadores destes impostos. Empresas agropecuárias apoiadas pela Superintendência de Desenvolvimento da Amazônia (SUDAM) seguem um "cronograma" para desmatamento, assegurando que esta seja feita o mais rápido possivel, embora nem todas as empresas consigam manter-se em dia com este calendário acelerado de desmatamento. $\mathrm{O}$ apelo destas ofertas de dinheiro, claramente, constitui uma grande motivação para o desmatamento. Há inclusive o problema de que incentivos tão generosos como estes podem tornar lucrativas as operações, que, quando baseadas nos seus próprios méritos, seriam anti-econômicas. Mesmo em casos em que o fazendeiro soubesse com toda clareza que o sistema de exploração a ser instalado, depois do desmatamento não é rentável ou competitivo, com outros possíveis investimentos alternativos, por causa da produção ou sustentabilidade insuficientes, o quadro econômico é alterado pela existência dos incentivos, fazendo com que este caminho de desenvolvimento seja seguido apesar dos problemas ecológicos, agronômicos e econômicos.

Qualquer tipo de desenvolvimento, apoiado por incentivos, corre o perigo de caminhar em rumos não aconselháveis sem o controle natural contra erros na estratégia desenvolvimentista, que seria presente em uma situaçãc de mercado livre, onde tais projetos, não justificáveis em termos estritamente econômicos, entrariam logo em falência, antes de ter desmatado muita área, para depois abandoná-la. Isto não quer dizer que todo e qualquer incentivo seja errado, mas tais incentivos deveriam ser muito mais restritos do que os atuais, deveriam ser muito melhor entendidos em termos dos seus impactos no desmatamento, e deveriam ser reavaliados continuamente, para não ficar em vigor depois de aparecer indicações de que a política seja errada. No caso de incentivos para estabelecimento de projetos de pecuária bovina, há bastante indicações de 
que este não se deve continuar, dada a existência de dúvidas quanto a sustentabilidade do sistema (Fearnside, 1979a, b). Incentivos, atualmente sendo oferecidos para a adubação de pastagens, o que, sem dúvida, prolonga a produtividade de pastagens degradadas (Serrão et al., 1978), deveriam ser examinados, para verificar se não está sendo encorajado, por conta dos incentivos, um sistema que não seria aconselhável em termos do seu próprio mérito econômico, à parte outras preocupações relativas ao desmatamento em geral. Se isso for o caso, seria uma motivação adicional para continuar desmatamentos em larga escala pouco justificáveis.

Além de pecuária bovina, diversos outros tipos de desenvolvimento são apoiados por incentivos. As plantações silviculturais e riziculturais da Jari Florestal e Agropecuária Ltda., por exemplo, gozam de vários incentivos, inclusive de isenção de imposto de renda e impostos sobre importação de equipamentos do exterior (Fearnside \& Rankin, 1979). Outros projetos para encorajar plantações comerciais de seringa, etc., também são incentivados, além de uma lista de diversos outros tipos de desenvolvimento não agricolas (Almeida, 1978). Provavelmente, projetos para exploração da floresta através de "contratos de utilização florestal" também seriam apoiados por tais incentivos. É importante que o impacto de todos os incentivos atuais e propostas sejam examinados em termos de efeitos sobre desmatamento e problemas ecológicos associados. Incentivos financeiros constituem uma das grandes causas de desmatamento na Amazônia, embora só se apliquem a uma parte da área explorada. Pode ser calculado dos dados de Tardin et al., (1978) que levantaram 445.843 hectares desmatados na área de mata, que $54,6 \%$ desta área eram projetos com incentivos da SUDAM.

Uma segunda motivação para desmatamen. to é conseqüência da disponibilidade de investimentos alternativos, o que torna o empresário individual na Amazônia pouco motivado a utilizar a sua terra de maneira sustentável, a longo prazo. A taxa de desconto usada para calcular o valor futuro do dinheiro não tem relação nenhuma com a taxa de exploração sus- tentável, o que é determinado por processos biológicos, como o tempo que leva uma árvore para crescer. Caso a tax de desconto seja superior à taxa de regeneração de um recurso potencialmente renovável, é de interesse eco. nômico do indivíduo destruir o recurso tão logo quanto possível, e reinvestir os lucros resultantes em qualquer outro projeto, muitas vezes num local diferente (Clark, 1973, 1976). Es. ta lógica aplica-se a muitas situações na Ama. zônia relativas ao desmatamento, para obter lucros, a curto prazo, sem preocupação com a sustentabilidade a longo prazo. A aplicabilidade desta lógica triste também deve ser estudada com urgência com relação à proposta de utilizar a floresta em grandes projetos madeireiros. Precisá-se de mecanismos econômicos para fazerem as compensações monetárias refletiram mais as exigências de sistemas sustentáveis desenhados para a Amazônia, o que tornaria estes sistemas econômicos e os atuais sistemas destrutivos anti-econômicos.

Um terceiro grande motivo para desmata. mento é o sistema atual de posse da terra na Amazônia. Há uma tradição muito antiga na Amazônia, segundo a qual o ato de desmatar uma área é o que dá direito de posse a uma pessoa. A função do sistema jurídico tem sido, em grande parte, a legalização posterior destes fatos consumados. Claramente este sistema dá a todo mundo uma motivação grande para desmatar a máxima área possível seja o "posseiro" um caboclo pobre ou uma empresa grande. Qualquer tentativa de limitar o desmatamento enquanto este sistema prevalecer, resultaria em fracasso, mesmo com toda dotação de regulamentos, fiscais, etc. A situação de quem é dono de cada área tem que ser esclarecida, e o costume de legitimar a posse do desmatador, ou então de compensá-lo por ter desmatado a área (o que é até chamado de "benfeitoria"), tem que acabar. O problema é que este sistema tradicional de posse da terra têm atuado durante séculos como uma "válvula de escape" para injustiças e desigualda. des extremas na situação fundiária do país, es. pecialmente em áreas mais populosas. Sem a opção de o pobre adquirir terra desta maneira, a situação dele tornar-se-ia intolerável. Por isso, qualquer esforço voltado a regularizar a 
situação fundiária na Amazônia, o que é uma prioridade urgente para qualquer plano de controlar desmatamento na área, teria que ser ligado com medidas para aliviar as desigualdades que atualmente estão sendo amenizadas pelo sistema de posseiros.

Uma quarta causa básica de desmatamento na Amazônia é o preço baixíssimo da terra. Terras loteadas pelo Instituto Nacional de Colonização e Reforma Agrária (INCRA) para fazendas de gado na área de Altamira, por exemplo, são vendidas a $2 \%$ do salário mínimo por hectare, e além disso com financiamento extremamente favorável ao comprador. Nestas condições, há pouca motivação para o fazen. deiro explorar áreas pequenas de terra usando técnicas que exigem muita máo-de-obra e/ ou capital, em vez de optar pela exploração extensiva, derrubando assim, vastas áreas, mesmo que este tipo de exploração não seja sus. tentável. Esforços do governo para encorajar técnicas mais caras, inclusive de manejo intensivo de pastagem, têm encontrado pouco êxito nestas condições econômicas. Precisa-se de medidas econômicas para manter o preço da terra suficientemente alto, para que os donos sejam motivados a empregar técnicas de produção sustentáveis em vez de derrubar sempre mais área.

Um quinto motivo para desmatamento é a simples necessidade de terra agrícola para sustentar a população humana crescente. Isto é complicado pelo uso da terra para a produção agrícola que não pretende apenas atender às necessidades mínimas da alimentação, mas também satisfazer a desejos de uma vida material melhor, os quais têm a tendência natural de crescer sem limite. Isto faz com que as áreas desmatadas para fins agrícolas sejam determinadas não pela capacidade limitada das barrigas do agricultor e sua família, para utilizar a produção, mas pelo limite da capacidade da mão-de-obra, capital, e terra que o agricultor tem à sua disposição. A relação entre o tamanho da população e os padrões de vida é básica quanto às questões relativas ao desmatamento, o que dá ainda mais ênfase à importância de estudos de capacidade de suporte.
Estas cinco causas de desmatamento têm que ser tratadas em qualquer política de desenvolvimento florestal na Amazônia visando ao controle do processo de desmatamento na região.

\section{CONTROLE DE DESMATAMENTO}

Como controlar o desmatamento é um dos problemas mais importantes e mais difíceis para qualquer política de desenvolvimento. $\mathrm{Na}$ Amazônia Brasileira, existe uma tradição com mais de 400 anos, de desprezar qualquer lei intencionada à preservação da flora e fauna da área (Sternberg, 1973). Além disso, há o problema geral no Brasil de um sistema onde $a$ lei é considerada como uma coisa só para ser aplicada contra "inimigos", e que sempre pode ser evitada pelo onipresente "jeito" (Rosenn, 1971). Há uma tradição desde a época colonial de manter milhares de leis em vigor, e de só aplicar algumas delas. Isto dificulta bastante a formulação de leis efetivas para controlar o desmatamento, e não é razoável esperar que este contexto do problema vá mudar em futuro próximo.

As leis atuais relativas ao desmatamento são interpretadas dentro deste contexto e não se fazem cumprir. Por exemplo, a lei exigindo que $50 \%$ de cada lote seja deixada sob floresta, foi primeiro reinterpretada pelos oficiais na área de colonização de Altamira para admitir a substituição da floresta por culturas "permanentes", um termo extremamente enganoso, que pode incluir além de culturas arborescentes, também culturas como pimenta do reino, e até cana-de-açúcar e pastagem. No final das contas, nem estas reinterpretações se fizeram valer, sendo que nenhum esforço para o cum. primento desta lei foi tentado. Há vários colonos na área de colonização de Altamira, em plena vista da rodovia, com todos os 100 hectares de seus lotes desmatados desde 1974, sem qualquer conseqüência jurídica. Entre as possibilidades para evitar a limitação desta lei, em outras áreas, onde a subdivisão de propriedades é mais comum, a conseqüência da venda separada destas reservas de $50 \%$ é óbvia.

Em Altamira, a situação mostra bem o pro. blema do cumprimento inadequado de leis flo- 
restais. A área sob a responsabilidade do escritório do Instituto Brasileiro de Desenvolvimento Florestal (IBDF) de Altamira estende-se aproximadamente $500 \mathrm{~km}$ ao longo da Rodovia Transamazônica em faixa de $200 \mathrm{~km}$ de largura, ou seja aproximadamente 100 mil quilômetros quadrados. Nesta área, está localizado o maior projeto de colonização dirigida na Transamazônica com umas 3.800 famílias de colonos (Brasil, INCRA, 1974) sendo extensas áreas colonizadas como "glebas" (fazendas de 500 ou 2.000 hectares), uma área de colonização antiga com acesso fluvial e a cidade de Altamira. O pessoal do IBDF responsável por esta área é constituído de três pessoas : um técnico e dois guardas. Esta turma está encarregada não só das leis relativas ao desmatamento, mas também da fiscalização para con. trolar exportação de peles e animais silvestres e a concessão de licenças para serraria: e exploração de madeira.

Foi anunciado recentemente, que a partir do ano agrícola 1979/80 haverá uma nova exigência : os colonos vão precisar de tirar uma licença para poder derrubar nos seus lotes. $\mathrm{Pa}$ rece que não há nenhum plano de aumentar a turma do IBDF na área, visando a esta exigência adicional. A eficácia do IBDF em fazer cumprir as leis florestais está obviamente limitada pelo problema endêmico de órgãos governamentais concentrarem a maioria dos seus recursos na administração central e de pouquíssimos recursos nos lugares afastados onde o cumprimento das leis realmente o exige. A fa!ta de fazer-se cumprir a lei também pode ser interpretada como indicador de que o governo considera o cumprimento destas leis de menos importância do que as muitas cutras atividades em que verbas maiores do governo estão sendo aplicadas, por exemplo. para incentivos financeiros para pecuária bovina.

A formulação de leis florestais adequadas tem uma série de complicações. Por exemplo, no caso da lei exigindo que $50 \%$ de cada propriedade seja deixado em mata, há uma certa injustiça: a exigência de que um pobre colono na Transamazônica reserve a metade dos seus recursos para proteger o meio ambiente é considerada razoável, enquanto uma exigência pa- ralela no caso de, vamos supor, uma firma industrial em São Paulo, seria impossível. Também há o problema de pequenas reservas deste tipo não servirem bem na função de manter populações naturais (Goodland \& (rwin, 1975). Além disso, a fiscalização adequada destas reservas já é muito difícil. No lado positivo, há probabilidade maior de os donos destas reservas particulares defenderem-nas contra posseiros, do que seria o caso com reservas governamentais.

Geralinente, leis visando à motivação de comportamento através de incentivos têm mais eficácia do que as que dependem da aplicação de multas ou outros castigos contra infratores, após o processo complicado de localizar e processar essas pessoas.

Dentro do possível, ecólogos precisam dar toda ajuda ao esforço de sugerir leis que seriam práticas e exeqüiveis que resultariam em controle efetivo do desmatamento e que serviriam melhor em termos da manutenção do meio ambiente. Estudos sobre quais são as necessidades para o cumprimento de leis florestais em termos de número de fiscais, sensoreamento remoto, verbas, etc., são de caráter urgente.

\section{USOS PLANEJADOS DA FLORESTA}

Os usos planejados da floresta são uma parte integral da política de seu desenvolvimento. Três tipos de usos são relevantes: usos da floresta derrubada, usos da floresta manejada e reservas ou parques.

Pesquisas na área de usos de terras desmatadas estão geralmente voltadas à melhoria de culturas e sistemas agrícolas. Normalmente, a prioridade mais alta é na obtenção de produções maiores. Eu sugeriria que às duas outras prioridades deveriam ser proporcionadas mais importância, do que ao problema de maximização de produção : aumento da confiabilidade é muito importante para o agricultor não correr muito risco de falha nas suas safras a cada ano; diversificação de culturas e variedades é uma técnica clássica para aumentar a confiabilidade. A ênfase de culturas perenes, tais como plantações de cacau, seringueira, dendê, fruteiras, ou plantações sil- 
viculturais é outra tendência que proporciona mais confiabilidade. Deve-se lembrar que os perigos com doenças, pragas, etc., que ameaçam monoculturas tanto perenes como anuais, são ainda mais prejudiciais, quando atacam monoculturas arborescentes (Janzen, 1973).

A sustentabilidade dos sistemas torna-se muito importante quando são consideradas as gerações futuras de brasileiros que vão morar na Amazônia, o que deveria ser de mais alta importância para o governo brasileiro na formulação da sua política para o desenvolvimento da região. Sustentabilidade também está ligada com o problema do desmatamento, pois a derrubada contínua e crescente de matá é a conseqüência inevitável, de sistemas não sustentáveis.

Os usos da floresta manejada oferecem a esperança de ser uma técnica para obter uma produção sustentada das vastas áreas de terra firme na Amazônia e, ao mesmo tempo, evitar muitos dos efeitos indesejáveis no clima, solo, biota, etc. associados com desmatamento total. Precisa-se de um exame minucioso de propostas atuais para projetos deste tipo, e programas acelerados de pesquisas básicas sobre a ecologia de florestas tropicais, sobre os efeitos de diferentes graus de perturbação e o comportamento de sistemas florestais manejados. O exame de propostas para "contratos de utilização florestal" (Schmithüsen, 1978) deve incluir conhecimento dos regulamentos propostos, os planos para replantio de mudas, para deixar matrizes, para enriquecer a floresta com espécies valiosas, e para a fiscalização e cumprimento desses regulamentos. A história triste de cumprimento de leis florestais dá razão para cautela. Mesmo planos que seriam adequados sob a hipótese de cumprimento perfeito da lei devem ser estimados para poderem prever-se os resultados de níveis de cumprimento mais realístico, ou seja, imperfeitos. Além das investigações ecológicas, precisa-se de dados econômicos, especialmente sobre os custos de extração, replantio, fiscalização, e defesa contra posseiros. Os efeitos de quaisquer incentivos financeiros também precisam ser estudados. Os níveis de rendimento a serem esperados precisam ser melhor conhecidos, além da consideração de como esta renda vai ser distribuída para sustentar a população na área. A escala enorme de projetos propostos totalizando ...... 39.504.000 hectares (Pandolfo, 1978) indica a necessidade de bastante mais experimentações, inclusive, de experimentos implantados em áreas fora das poucas áreas estudadas até agora na Estação Experimental de Curuá-Una e na Floresta Nacional de Tapajós, como sempre foi notado pelos proponentes deste tipo de manejo (Reis, 1978). Mesmo nas áreas onde estudos já estão em progresso, a situação é descrita pelo especialista Reis (1978) assim : “ $\mathrm{Na}$ verdade, um sistema de produção autosustentada da floresta tropical densa, para fins industriais, baseado no modelo aqui considerado, ainda não foi desenvolvido". Quer dizer : precisa-se muito de pesquisa, o que deve ser de alta prioridade, especialmente para ecólogos com interesse no desenvolvimento.

Reservas e parques, inclusive de parques nacionais, florestas nacionais, reservas florestais, reservas ecológicas, reservas indígenas, reservas biológicas, etc., constituem usos planejados da floresta sobre os quais a opinião de ecólogos é indispensável. Precisa-se de argumentos baseados em dados para justificar o número, tamanho, localização e restrição contra perturbações destes parques. A tomada de medidas adequadas para salvaguardar estas áreas contra invasão é essencial. A opiniāo de que as reservas e parques não são adequadas e não são suficientemente protegidas contra invasão é a opinião geral entre pesquisadores que trabalham neste ramo.

\section{CONCLUSÕES}

As seis áreas de pesquisa em que ecólogos podem contribuir para a formulação de diretrizes para o desenvolvimento na Amazônia abrangem campos de conhecimento amplos e interdisciplinares. Além destas seis áreas, há muitas outras também importantes, tais como política energética, política de transportes, mineração, desenvolvimento de represas, pesca, poluição e os efeitos do urbanismo e industrialização crescente na região amazônica. 


\section{BIBLIOGRAFIA}

ALMEIDA, H. DE

1978 - o desenvolvimento da Amazônia e a política de incentivos fiscais. Superintendência de Desenvolvimento da Amazônia (SUDAM), Belém. 32p.

Brasil, Instituto Nacional de Colonização e Reforma Agrária (INCRA)

Coordenadoria Regional do Norte CR-01.

1974 - Relatório de Atividades. INCRA, Belém. 1974.

CLARK, C. W.

1973 - The economics of Overexploitation. Science, 181: 630-634.

1976 - Mathematical Bioeconomics : the Optimal management of renewable resources. Wiley-Interscience, N.Y. 352p.

FeARNSIDE, P. M.

1979a- Os efeitos das pastagens sobre a fertilidade do solo na Amazônia Brasileira: conseqüências para sustentabilidade de produção bovina. Acta Amazonica : (no prelo).

1979b- Previsão de produção bovina na Transamazônica do Brasil. Acta Amazonica 9 (4): 689-700.

1979c- The development of the Amazon Rain Forest : priority problems for the formulation of guidelines. Interciência, 4 (6): 338-343.

FEARNSIDE, P. M. \& RANkin, J. M.

1979 - Avaliação do Jari Florestal e Agropecuária Ltda. como modelo para o desenvolvimento da Amazônia. Acta Amazonica, 9 (3): 609-615.

Goodland, R. J. A. \& IRwin, H. S.

1975 - Amazon jungle: green hell to red desert? an ecological discussion of the environmental impact of the highway construction program in the Amazon basin. Elsevier, N.Y. 155p.

JANZEN, D. H.

1973 - Tropical agroecosystems : habitats misunderstood by the temperate zones, mismaneged by the tropics. Science, 182: 12121219.

PANDOLFO, C.

\footnotetext{
1978 - A floresta amazônica brasileira : enfoque econômico-ecológico. Superintendência do Desenvolvimento da Amazônia (SUDAM), Belém. 118p.
}

REIS, M, S.

1978 - Uma definição técnica-política para o aproveitamento racional dos recursos florestais da Amazônia Brasileira. (Conferência proferida durante o 3o. Congresso Florestal Brasileiro, Manaus, Amazonas, 04-07 de dezembro de 1978). Projeto de Desenvolvimento e Pesquisa Florestal (PRODEPEF), Instituto Brasileiro de Desenvolvimento Florestal (IBDF), Brasília. 21p.

ROsENN, K. S.

1971 - The jeito: Brazil's institutional bypass of the formal legal system and its development implications. The American Journal of Comparative Law, 19: 514-549.

SCHMITHÜSEN, F.

1978 - Contratos de utilização florestal com referência especial a Amazônia Brasilleira. [PNUD/FAO/IBDF/BRA/76/027, Série Técnica N. 12), Projeto de Desenvolvimento e Pesquisa Florestal (PRODEPEF), Brasília. $35 p$.

Serrão, E. A. S.; Falesi, I. C.; Da Viega, J. B. \& Neto, J. F. T.

1978 - Produtividade de pastagens cultivadas em solos de baixa fertilidade das áreas de floresta do Trópico Úmido brasileiro. Empresa Brasileira de Pesquisa Agropecuária (EMBRAPA], Centro de Pesquisa Agropecuária do Trópico Úmido (CPATU). Belém. 73p.

STERNBERG, H. O. R.

1973 - Development and conservation. Erdkunde, Archiv. für wissenschaftliche Geographie, Band 27, 1fg. 4 Bonn. p. 263-265 (reeditado por: Center for Latin American Studies, University of California, Berkeley, Reprint 447).

Tardin, A.T.; Santos, A.P. dos; Moraes Novo, E.M.L. \& TOLEDO, F.L.

1978 - Projetos agropecuários da Amazônia; Desmatamento e fiscalização - relatćrio. A Amazônia Brasileira em Foco, (12): 7-45.

Tardin, A.T.; Santos, A. P. Dos; Lee, D. C. L.; Maia, F.C.S.; MENDONÇ.A, F.J.; Assunção, C. V.;

RoIRIgues, J. E.; MOURA ABdon, DE M.; Novaes R. A.; Chen, S. C.; Duarte, V. \& Shimabukuro, Y. E.

1979 - Levantamento de áreas de desmatamento na Amazônia Legal através de imagens de satélite LANDSAT. (INPE-COM.3/NTE,C.D.U. 621.38SR). Instituto Nacional de Pesquisas Espaciais, São José dos Campos, São Paulo. $9 p$. 